\title{
Colorimetric Determination of Stability Constant of Sulfamethoxazole-Cu(II) Complex at Different Temperatures by Continuous Variation Method
}

\author{
O.V. Ikpeazu ${ }^{1}$ \\ Department of Biochemistry, \\ Abia State University, Uturu
}

\author{
I.E. Otuokere ${ }^{2}$ \\ Department of Chemistry, \\ Michael Okpara University of Agriculture, \\ Umudike, Nigeria
}

\begin{abstract}
Sulfamethoxazole is an antibiotic that is used for the treatment of bacterial infections such as prostatitis, bronchitis and urinary tract infections. It is effective against gram negative and gram positive bacteria. Classical equation has been used in the calculation of stability constant of Sulfamethoxazole$\mathrm{Cu}$ (II) complex depending on the theoretical explanation of the stoichiometry. The formation of $\mathrm{Cu}$ (II) complex with sulfamethoxazole was studied colorimetrically at an absorption maximum of $430 \mathrm{~nm}$ at $25,30,35$ and $40{ }^{\circ} \mathrm{C}$. The data showed that $\mathrm{Cu}(\mathrm{II})$ and sulfamethoxazole combine in the molar ratio of $1: 2$ at pH 7.4 with ionic strength maintained using $0.1 \mathrm{M}$ $\mathrm{KNO}_{3}$. Calculated stability constants values were $4.02 \mathrm{x}$ $10^{6}, 2.93 \times 10^{6}, 1.37 \times 10^{6}$ and $9.21 \times 10^{5}$ using continuous variation method. Calculated $\Delta \mathbf{G}^{\boldsymbol{\theta}}$ for the complex were $-3.77 \times 10^{4},-3.75 \times 10^{4},-3.62 \times 10^{4}$ and $3.57 \times 10^{4}$. The stoichiometry, stability constant and Gibbs free energy results suggested that sulfamethoxazole used in the study is a good chelating agent and can be an efficient antidote in the therapy of $\mathrm{Cu}(\mathrm{II})$ overload or poisoning.
\end{abstract}

Keywords:- Sulfamethoxazole, Copper, Complex, Stability Constant.

\section{INTRODUCTION}

Sulfamethoxazole is an antibiotic that is used for the treatment of bacterial infections such as prostatitis, bronchitis and urinary tract infections. It is effective against gram negative and gram positive bacteria [1]. It is a sulfonamide and bacteriostatic agent. Sulfamethoxazole prevents the synthesis of folic acid in the bacteria that must synthesize their own folic acid. Bacteria that require performed folic acid (vitamin B9) are insensitive to sulfamethoxazole [2]. It was first introduced in America in 1961[3]. It is always administered in combination with trimethoprim (abbreviated SMX-TMP) [4].

Absorption of copper occurs in the gut and it is transported to the liver bound to albumin. It enters the bloodstream through the plasma protein known as ceruloplasmin. Copper metabolism is controlled in the

\author{
K.K.Igwe ${ }^{3}$ \\ Department of Vet. Biochemistry and Animal Production, \\ Michael Okpara University of Agriculture, \\ Umudike, Nigeria
}

liver and excreted in bile [5]. Copper is transported to the cells through copper membrane transporter 1 (CMTI), where it coordinate to metallothioneins to the trans- golgi network. Ceruloplamin is responsible for carrying $9 \%$ of copper in the blood to tissues that need the mineral $[6,7]$. Excessive dose of copper is a lingering problem because excretion of cooper is so slow, only $10 \%$ can be excreted in 72 hours [5].

The ligational, spectroscopic and evaluating antimicrobial investigations of sulfamethoxazole (SMX) drug complexes formulas with $\mathrm{Mn}$ (II), $\mathrm{Cu}$ (II), $\mathrm{Ni}$ (II), $\mathrm{Zn}(\mathrm{II}), \mathrm{Y}(\mathrm{III}), \mathrm{La}(\mathrm{III}), \mathrm{Nd}(\mathrm{III})$ and Gd(III) metal ions have been reported [8]. These sulfamethoxazole complexes were synthesized and characterized by elemental analysis, molar conductance, magnetic susceptibility, UV-vis, IR and $1 \mathrm{H}-$ NMR spectroscopy. The IR spectral data suggested that the coordination sites of SMX are the sulfonyloxygen and $\mathrm{SO}_{2-}$ $\mathrm{NH}$ sulfonamide nitrogen as a bidentate ligand. From the microanalytical data, the stoichiometry of the complexes was 1:2 (metal: ligand).

For several decades, chelating agents have been used as antidote to combat metal poisoning [9]. Biological friendly sequestrating agents have been used effectively to chelate metals in patients with metal overload [9]. However, chelating capacity is a function of stability constant indicating that the effectiveness of a drug to chelate with a metal ion depends on the stability constant and other parameters [10] Many authors have reported the study of stability constant of drug- metal complexes [11, 12]. However, to the best of our knowledge, the stability constant of sulfamethoxazole-Cu(II) complex at different temperatures have not been reported elsewhere in literature. Therefore, the present study is aimed at determining the stability constant of sulfamethoxazole-Cu(II) complex using continuous variation

Information on stability constants of this complex can be useful in analysisng the effects of sulfamethoxazole on copper ion and other electroactive divalent trace metals. It is possible that changes in trace metal and mineral concentration induced by sulfamethoxazole can be an efficient antidote in the therapy of $\mathrm{Cu}$ overload or 
poisoning. The chemical structure of sulfamethoxazole is shown in Fig. 1 while the chemical structure of the proposed complexes is shown in Fig. 2.

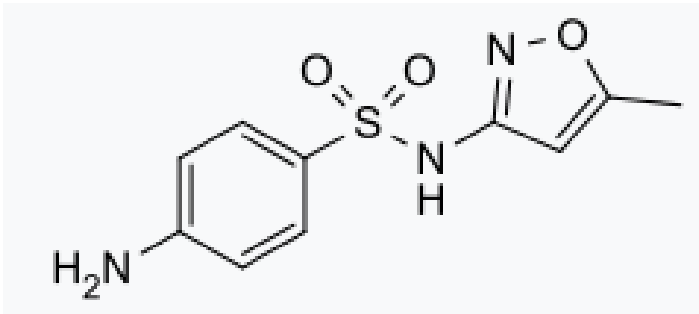

Fig 1:- Chemical structure of sulfamethoxazole

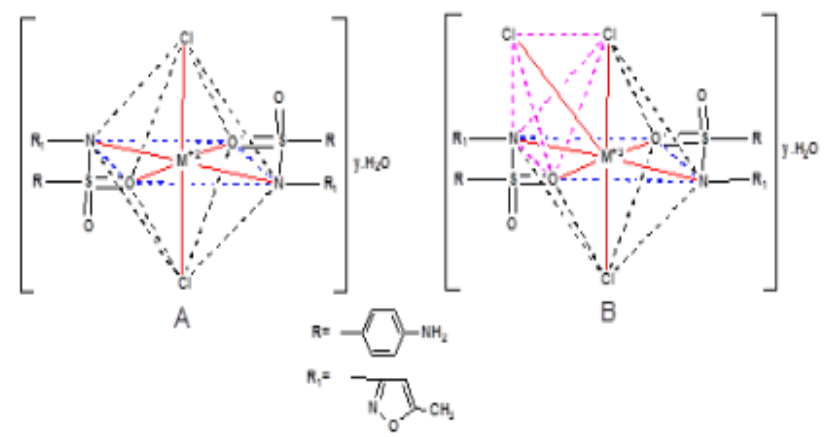

Fig 2: Geometry of sulfamethoxazole complexes

\section{MATERIALS AND METHODS}

\section{Reagents}

Reagents used for the study were of analytical grade. Sulfamethoxazole was purchased from Andhra Organics Limited, Indian. $\mathrm{CuSO}_{4}$ was purchased from Merck \& Co., Inc USA. Double-distilled water was used throughout the experiment.

\section{Preparation of $1 \times 10^{-2} \mathrm{M} \mathrm{CuSO}_{4}$}

$\mathrm{CuSO}_{4}(1.566 \mathrm{~g}, 10 \mathrm{Mmol}$, molar weight $=156.60$ $\mathrm{g} / \mathrm{mol}$ ) was dissolved in freshly distilled water contained in a $250 \mathrm{~cm}^{3}$ beaker and was made up to the mark in a 1000 $\mathrm{cm}^{3}$ volumetric flask.

\section{Preparation of $1 \times 10^{-2} \mathrm{M}$ sulfamethoxazole}

sulfamethoxazole $(2.532 \mathrm{~g}, 10 \mathrm{Mmol}$ molar weight = $253.279 \mathrm{~g} / \mathrm{mol}$ ) was dissolved in freshly distilled water in a $250 \mathrm{~cm}^{3}$ beaker and was made up to the mark in a $1000 \mathrm{~cm}^{3}$ volumetric flask.

\section{Procedure for continuous variation method}

Exactly $0,1,2,3,4,5,6 \mathrm{~cm}^{3}$ of $1 \times 10^{-2} \mathrm{M} \mathrm{CuSO}_{4}$ were pipetted into seven different $50 \mathrm{~cm}^{3}$ volumetric flasks respectively. Exactly 6, 5, 4, 3, 2, 1, $0 \mathrm{~cm}^{3}$ of $1 \times 10^{-2} \mathrm{M}$ of sulfamethoxazole was added to the respective flasks containing $\mathrm{Cu}(\mathrm{II})$ solution. The $\mathrm{pH}$ was adjusted to 7.4 while the ionic strength was maintained constant using 0.1 $\mathrm{M} \mathrm{KNO}_{3}$. The absorbance of each solution was measured at $430 \mathrm{~nm}$ (maximum wavelength of absorbance of the complex) and at temperatures of 25 and $40^{\circ} \mathrm{C}$, respectively.

Calculation of stoichiometry, stability constant and free energy

The stoichiometry mole fraction (SMF) of the complex using continuous variation method was calculated using equation 1 [14].

$S M F=\frac{m}{1-m}$

where $\mathrm{m}$ is the mole fraction of the metal ion. The stability constant was calculated using the classical method expressed in equation 2 ,

$K_{s t}=\frac{1-\alpha}{m^{m} \cdot n^{n}(\alpha)^{m+n}(C)^{m+n-1}}$

where $\mathrm{C}$ is the concentration of the complex at stoichiometry point, $\alpha$ is the degree of dissociation, $m$ and $n$ are the corresponding stoichiometric coefficients of metal and ligand respectively. The degree of dissociation $(\alpha)$ was calculated using equations 3, 4 and 5 [14].

$A_{\alpha}=A_{o}-A_{\text {max }}$
$A_{\text {max }}=\varepsilon b C$
$\alpha=\frac{A_{\alpha}}{\varepsilon b C}$

where $A_{\max }$ is absorbance value of the maximum at experimental curve that represents the maximum quantity of the complex that is formed. $A_{o}$ is absorbance value corresponding to the intersect point of the theoretical straight lines. $A_{\alpha}$ is the absorbance value of the part of dissociated concentration of complex. $\varepsilon$ is molar absorptivity, $\mathrm{b}$ is cell thickness, $\mathrm{C}$ is a concentration of complex at stoichiometry point.

The Gibbs free energy was calculated using the Helmholtz Gibb equation (equation 6),

$\Delta G^{\theta}=-R T \operatorname{In} K$ 


\section{RESULTS AND DISCUSSION}

The absorption spectra of sulfamethoxazole-Cu(II) complex is shown in Fig. 3

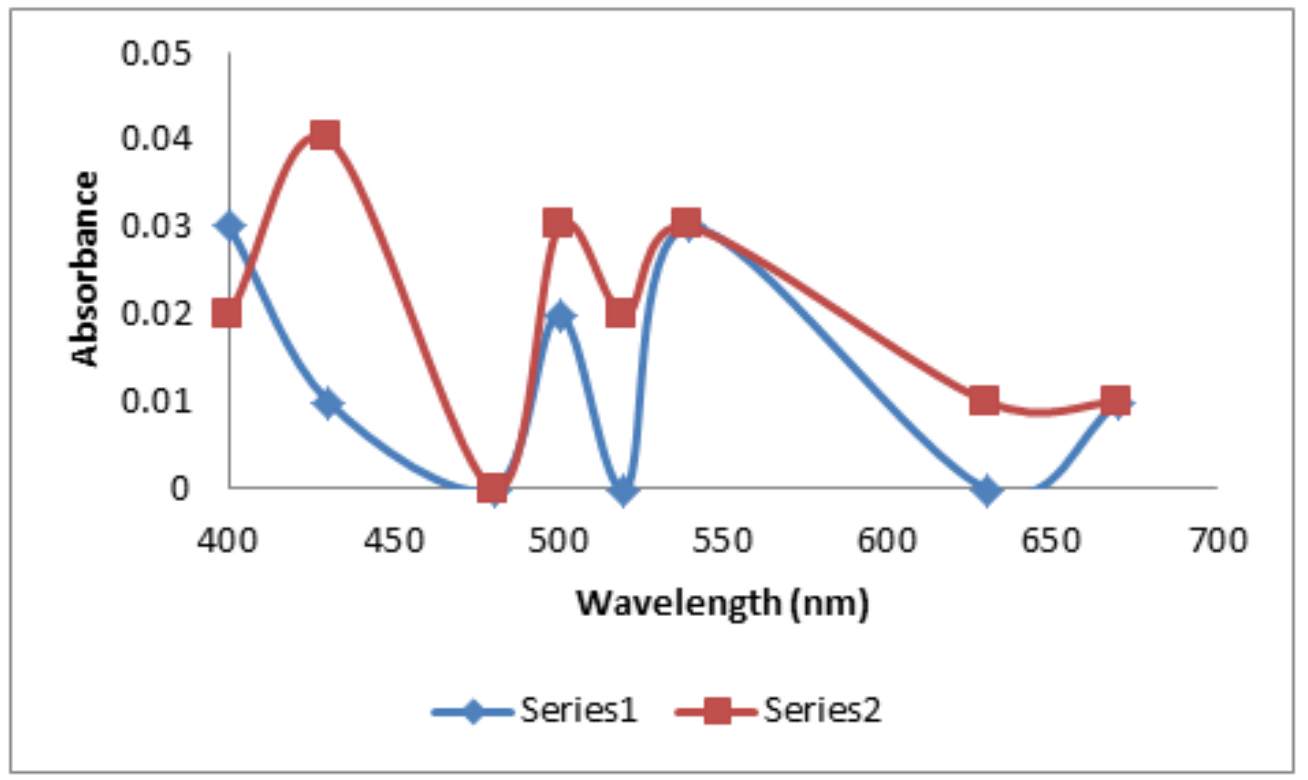

Fig 3:- Absorption spectra of $\mathrm{CuSO}_{4}\left(1 \times 10^{-2} \mathrm{M}\right)$ (series 1) and sulfamethoxazole-Cu(II) complex (series 2)

The absorption spectra (Fig. 3) shows the absorbance of $\mathrm{CuSO}_{4}$ (series 1) and sulfamethoxazole-Cu(II) complex (series 2) at wavelength of $400-700 \mathrm{~nm}$. It was observed that the wavelength of maximum absorbance of the complex was $430 \mathrm{~nm}$. At this wavelength, $\mathrm{CuSO}_{4}$ displayed minimal absorbance. Since the complex maximum absorbance was $430 \mathrm{~nm}$, it was used for the analytical measurement in the determination of the stoichiometry, stability constants and free energies. The maximum absorbance of $\mathrm{CuSO}_{4}$ was observed at wavelength of $540 \mathrm{~nm}$. It was observed that sulfamethoxazole-Cu(II) complex gave a water soluble complex in aqueous solution, This may be attributed to the ability of water to act as a weak monodentate ligand in forming labile $\mathrm{Cu}$-aquo complex. During complexation, sulfamethoxazole displaced water from Cu-aquo to form a stable sulfamethoxazole$\mathrm{Cu}$ (II) complex. Similar labile aquo complexes were also proposed by Tirmizi and co-workers in their study of famotidine-Cu complex and cimetidine-Ni complex $[11,12]$. Labile aquo complex was also reported by Tella and co-workers in their study of acetaminophen- $\mathrm{Cu}(\mathrm{II})$ stability constants [9].

\begin{tabular}{|c|c|c|c|c|c|c|c|}
\hline \multirow[t]{2}{*}{$\mathrm{S} / \mathrm{N}$} & \multirow[t]{2}{*}{$\begin{array}{c}\mathrm{CuSO}_{4} \\
\left(1 \times 10^{-2} \mathrm{M}\right)\end{array}$} & \multirow[t]{2}{*}{$\begin{array}{l}\text { Sulfamethoxazole } \\
\qquad\left(1 \times 10^{-2} \mathrm{M}\right)\end{array}$} & \multirow{2}{*}{$\begin{array}{c}\text { Mole } \\
\text { fraction of } \\
\mathrm{Cu}(\mathrm{II})\end{array}$} & \multicolumn{2}{|c|}{$\begin{array}{c}\text { Absorbance at } \\
430(\mathrm{~nm})\end{array}$} & \multirow[b]{2}{*}{$35^{\circ} \mathrm{C}$} & \multirow[b]{2}{*}{$40^{\circ} \mathrm{C}$} \\
\hline & & & & $25^{\circ} \mathrm{C}$ & $30^{\circ} \mathrm{C}$ & & \\
\hline 1 & 0.000 & 6.000 & 0.000 & 0.00 & 0.01 & 0.01 & 0.01 \\
\hline 2 & 1.000 & 5.000 & 0.170 & 0.02 & 0.02 & 0.02 & 0.02 \\
\hline 3 & 2.000 & 4.000 & 0.330 & 0.03 & 0.03 & 0.03 & 0.03 \\
\hline 4 & 3.000 & 3.000 & 0.500 & 0.05 & 0.04 & 0.05 & 0.05 \\
\hline 5 & 4.000 & 2.000 & 0.660 & 0.06 & 0.07 & 0.06 & 0.06 \\
\hline 6 & 5.000 & 1.000 & 0.830 & 0.03 & 0.03 & 0.03 & 0.03 \\
\hline 7 & 6.000 & 0.000 & 1.000 & 0.01 & 0.02 & 0.01 & 0.02 \\
\hline
\end{tabular}

Table 1:- Experimental data of sulfamethoxazole-Cu(II) complex at $430 \mathrm{~nm}$ by continuous variation method 


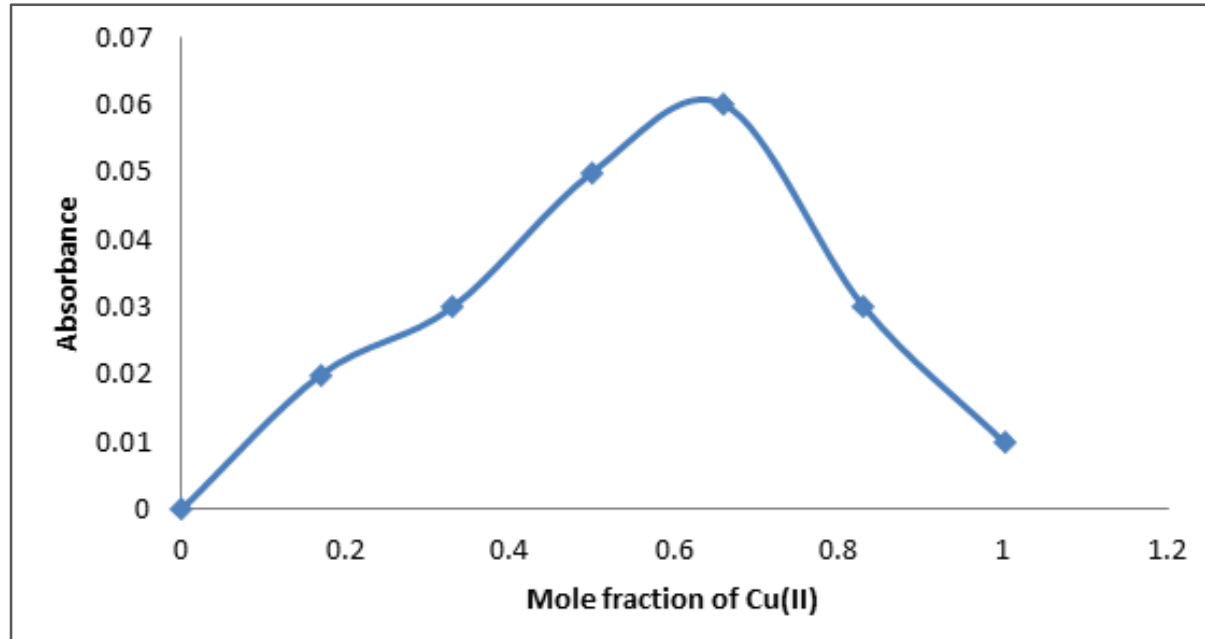

Fig 4:- Job's curve of equimolar solutions at $25^{\circ} \mathrm{C}$

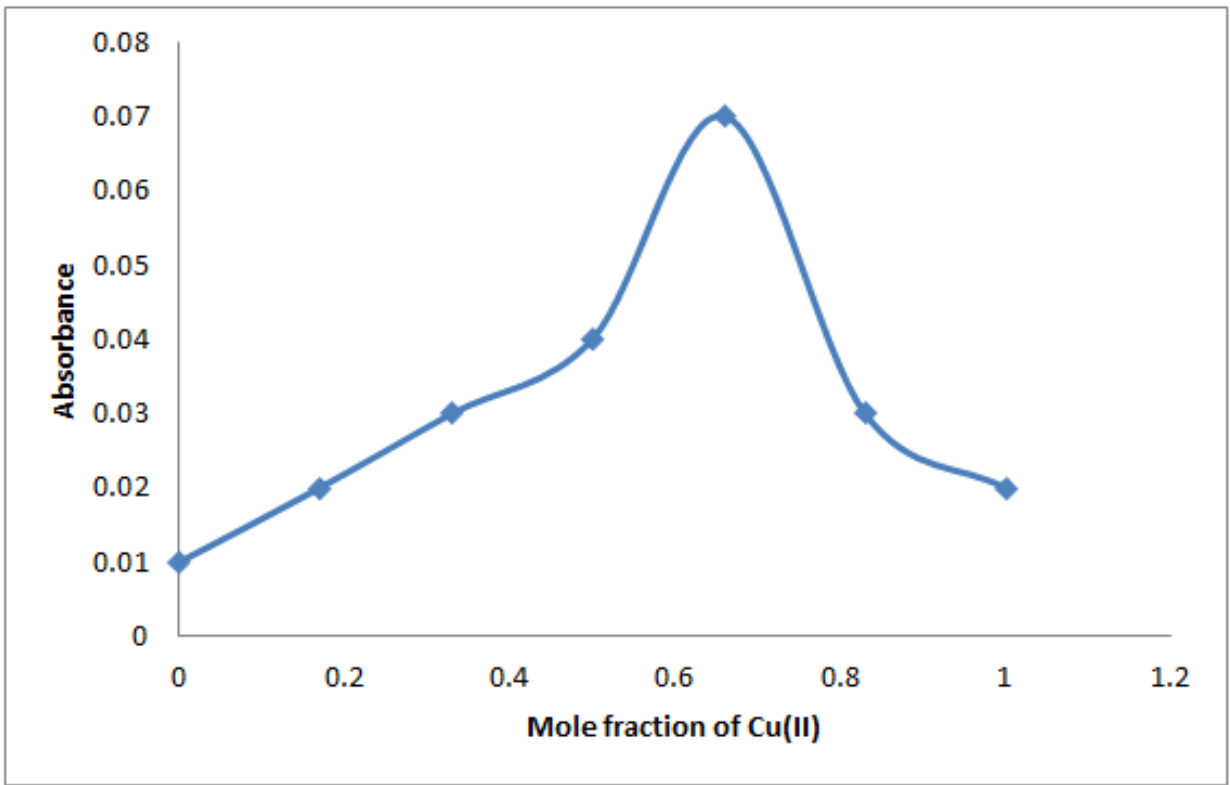

Fig 5:- Job's curve of equimolar solutions at $30^{\circ} \mathrm{C}$

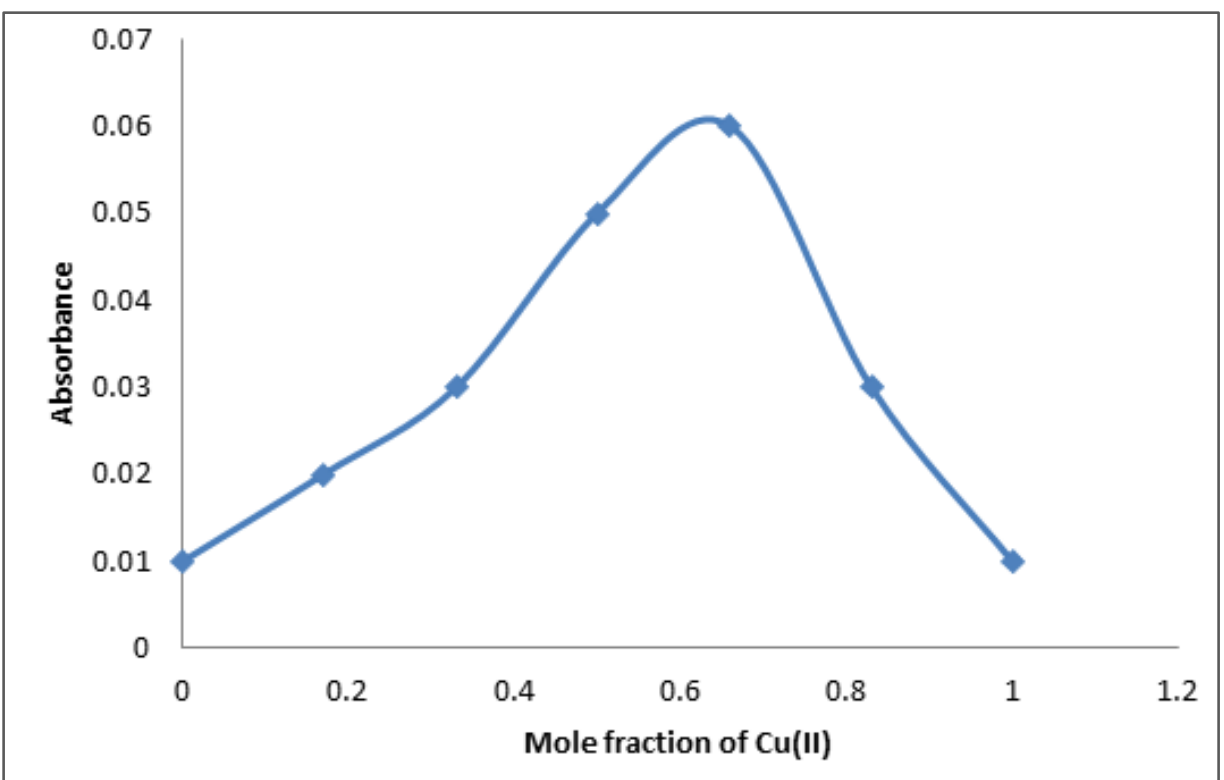

Fig 6:- Job's curve of equimolar solutions at $35^{\circ} \mathrm{C}$ 


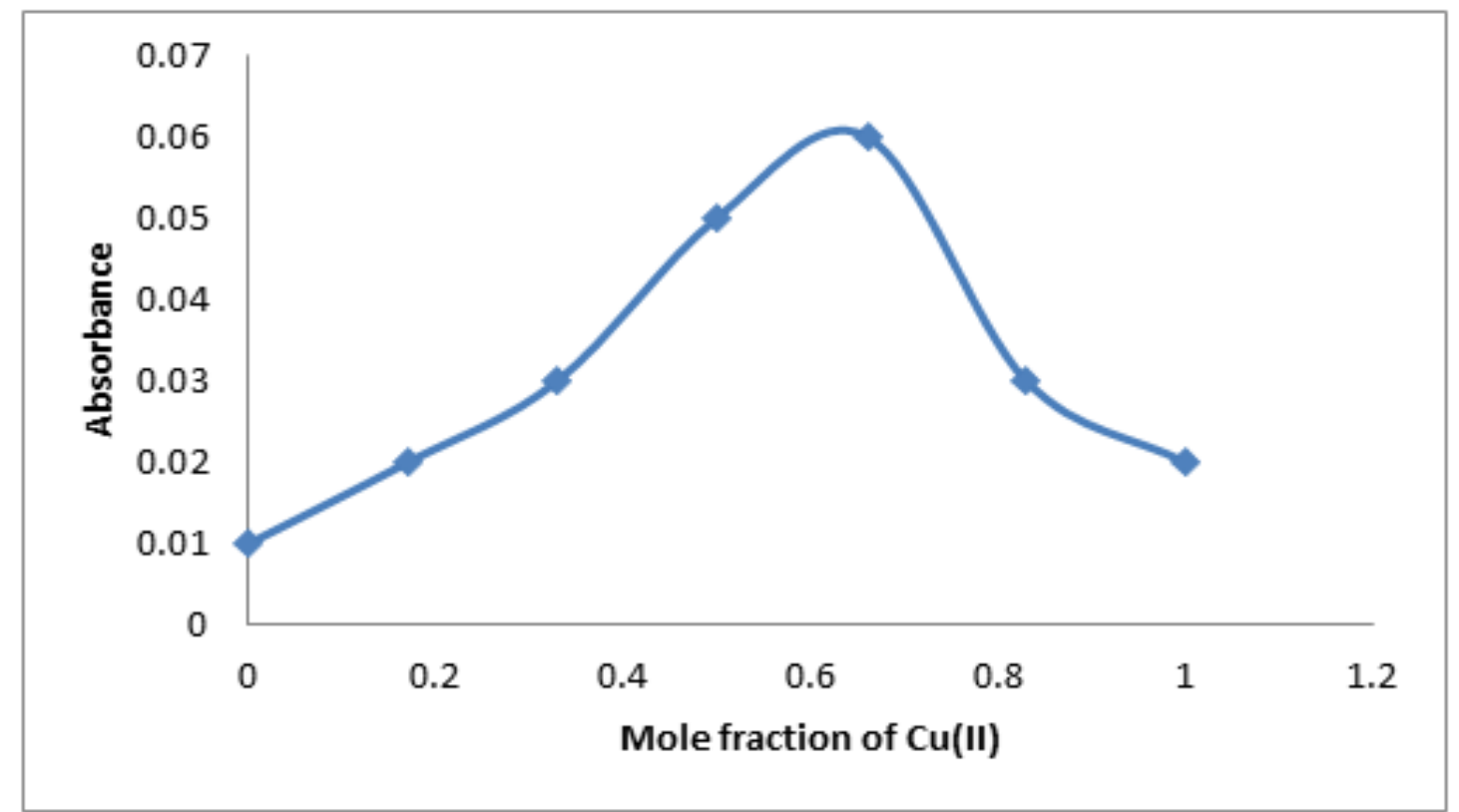

Fig 7:- Job's curve of equimolar solutions at $40^{\circ} \mathrm{C}$

The Job's curves at 25, 30, 35 and $40{ }^{\circ} \mathrm{C}$ are shown in Figures 4, 5, 6 and 7 respectively. Equation 1 was applied in calculation of stoichiometry.

$$
\begin{aligned}
& S M F=\frac{0.65}{0.35}=1.85 \approx 2 \quad\left(\text { at } 25 \quad{ }^{0} \mathrm{C}\right), \quad S M F=\frac{0.66}{0.34}= \\
& 1.94 \approx 2\left(\text { at } 30 \quad{ }^{\circ} \mathrm{C}\right), S M F=\frac{0.65}{0.35}=1.85 \approx 2 \quad(\text { at } 35 \\
& \left.{ }^{\circ} \mathrm{C}\right), S M F=\frac{0.65}{0.35}=1.85 \approx 2\left(\text { at } 40^{\circ} \mathrm{C}\right) .
\end{aligned}
$$

This corresponded to metal:ligand ratio of 1:2. The extrapolated value at the point of cross-section on continuous variation plot (Figs. 4, 5, 6 and 7) corresponded to the total absorbance of the complex, indicating that the complex formation process has been completed. Several authors have also applied continuous variation method in the determination of metal:ligand ratio in complexes $[13,14]$.

\begin{tabular}{|c|c|c|c|c|}
\hline $\mathbf{S} / \mathbf{N}$ & Temperature $\left({ }^{\circ} \mathbf{C}\right)$ & M:L ratio & Stability constant & $\begin{array}{c}\Delta \mathbf{G}^{\boldsymbol{\theta}} \\
(\mathbf{J})\end{array}$ \\
\hline 1 & 25 & $1: 2$ & $4.02 \times 10^{6}$ & $3.77 \times 10^{4}$ \\
\hline 2 & 30 & $1: 2$ & $2.93 \times 10^{6}$ & $3.75 \times 10^{4}$ \\
\hline 3 & 35 & $1: 2$ & $1.37 \times 10^{6}$ & $3.62 \times 10^{4}$ \\
\hline 4 & 40 & $1: 2$ & $9.21 \times 10^{5}$ & $3.57 \times 10^{4}$ \\
\hline
\end{tabular}

Table 2:- Calculated stability constant and Gibbs free energies of sulfamethoxazole-Cu(II) complex using continuous variation method

Stability constant is an evaluation of the strength of the interaction between the reagents that come together to form the complex. Large values indicate that the metal has high affinity for the ligand, provided the system is at equilibrium. Calculation of the stability constant and Gibbs free energies were based on equations 2, 3, 4, 5 and 6 respectively. The values of the stability constant showed that the complex was stable at $25,30,35$ and $40{ }^{\circ} \mathrm{C}$. Increasing the temperature of coordination from 25 to $40{ }^{\circ} \mathrm{C}$ did not display observable significant effect on the stability constant. The values of the stability constants were positive, indicating that the complex is stable. Positive stability constant values using continuous variation have also been reported by several authors [ $9-14]$. Continuous variation is an established techniques in the determination of stability constant and Gibbs free energies. The results of stability constant suggested that sulfamethoxazole could be effective in chelation therapy against $\mathrm{Cu}$ (II) toxicity. The negative values of the free energies suggested that the complexes were formed spontaneously.

\section{CONCLUSION}

Sulfamethoxazole is an antibiotic that is used for the treatment of bacterial infections such as prostatitis, bronchitis and urinary tract infections. It formed a reasonably stable complex with $\mathrm{Cu}(\mathrm{II})$. The Job's continuous variation methods data showed that $\mathrm{Cu}$ (II) and sulfamethozaxole combine in the molar ratio of $1: 2$. The stability constant results suggested that sulfamethozaxole used in the study is a good chelating agent and can be an efficient antidote in the therapy of $\mathrm{Cu}$ (II) overload or poisoning. 


\section{REFERENCES}

[1]. "Sulfamethoxazole". DrugBank. Retrieved 5 November 2015.

[2]. Brunton; et al. (2011). Goodman and Gilman's The pharmacological Basis of Therapeautics. The McGraw-Hill Companies, Inc. pp. 1463-1469.

[3]. Pharmaceutical Manufacturing Encyclopedia, 3rd Edition. William Andrew Publishing. 2013-10-22.

[4]. SMZ-TMP in Abstract of "Cutaneous hypersensitivity to sulfamethoxazole-trimethoprim (SMZ TMP) in HIV infected patients" at nlm.nih.gov

[5]. E.D. Harris. Copper homeostasis: the role of cellular transporters. Nutr Rev, Vol. 59, pp. 281-285, 2001.

[6]. J.L. Groff, S.S. Gropper, S.M. Hunt. Advanced Nutrition and Human Metabolism. West Publishing Company, New York. 1995.

[7]. S.J. Adelstein and B.L. Vallee. Copper metabolism in man. New England Journal of Medicine Vol. 265, pp. 892-897.1961

[8]. Y.M.S. Jamil, M.A. Al-Maqtari and M.K. Al-qadasi, ligational and spectroscopic on some sulfamethoxazole metal complexes as antimicrobial agents, European Journal of Pharmaceutical and Medical Research Vol. 4(07), pp. 95-105. 2017

[9]. O.V. Ikpeazu, I.E. Otuokere and K.K..Igwe Acetaminophen-Mn(II) complex: determination of stoichiometry,stability constants and Gibbs free energies at different temperatures, Nigerian Research Journal of Chemical Sciences Vol. 8, Issue 2. pp. 98 110,2020

[10]. A.C. Tella, \& J.A. Obaleye, "Metal-Chelator Therapy: Stability Constatnt of Transition metal complexes of Pyrimidine and Sulphonamide Drugs. Int. Chem. Sci. Vol. 8, No. 3, pp.1675, 2010

[11]. S.A. Tirmizi, M.H. Sarwar, W.S. Sarwar \& W. Anwar, "Spectrophotometric study of stability constants of famotidine-Cu(II) complex at different temperatures", The Arabian Journal for Science and Engineering, Vol. 34, No, 2A, pp. 43, 2008

[12]. S.A. Tirmizi, F.H. Wattoo, M.H.S. Wattoo, S. Sarwar, A.N. Memon, and A.B. Ghangro, "Spectrophotometric study of stability constants of cimetidine-Ni(II) complex at different temperatures", Arabian Journal of Chemistry, Vol. 5, pp.309 - 314, 2012

[13]. R. Waranyoupalin, R., Wongnawa, S., Wongnawa, M., Pakawatchai, C., Panichayupakaranant, P. \&Sherdshoopongse, P. "Studies of complex formation between curcumin and $\mathrm{Hg}$ (II) by spectrophotometric method: A new approach to overcome peak overlap",Cent. Eur. J. Chem., Vol. 7, No.3, pp. 388, 2009

[14]. R.F. Abbas, (2017). Spectrophotometric determination of stability constant by classical and Modified Varagas equations for procaine penicillin $G$ using diazotization reaction depending on stoichiometric curves, International Journal of ChemTech Research, Vol. 10, No. 2, pp. 485 - 496. 2017 